\title{
Protective Effects of Liposomal N-Acetylcysteine against Paraquat-Induced Cytotoxicity and Gene Expression
}

\author{
Panagiotis Mitsopoulos $^{1,2}$ and Zacharias E. Suntres ${ }^{1,2}$ \\ ${ }^{1}$ Medical Sciences Division, Northern Ontario School of Medicine, Thunder Bay, ON, Canada P7B 5E1 \\ ${ }^{2}$ Department of Biology, Lakehead University, Thunder Bay, ON, Canada P7B 5E1
}

Correspondence should be addressed to Zacharias E. Suntres, zacharias.suntres@nosm.ca

Received 3 December 2010; Revised 20 January 2011; Accepted 31 January 2011

Academic Editor: P. J. O’Brien

Copyright (C 2011 P. Mitsopoulos and Z. E. Suntres. This is an open access article distributed under the Creative Commons Attribution License, which permits unrestricted use, distribution, and reproduction in any medium, provided the original work is properly cited.

\begin{abstract}
Paraquat (PQ) is a herbicide that preferentially accumulates in the lung and exerts its cytotoxicity via the generation of reactive oxygen species (ROS). There is no specific treatment for paraquat poisoning. Attempts have been made to increase the antioxidant status in the lung using antioxidants (e.g., superoxide dismutase, vitamin E, N-acetylcysteine) but the outcome from such treatments is limited. Encapsulation of antioxidants in liposomes improves their therapeutic potential against oxidant-induced lung damage because liposomes facilitate intracellular delivery and prolong the retention of entrapped agents inside the cell. In the present study, we compared the effectiveness of conventional N-acetylcysteine (NAC) and liposomal-NAC (L-NAC) against PQ-induced cytotoxicity and examined the mechanism(s) by which these antioxidant formulations conferred cytoprotection. The effects of NAC or L-NAC against PQ-induced cytotoxicity in A549 cells were assessed by measuring cellular PQ uptake, intracellular glutathione content, ROS levels, mitochondrial membrane potential, cellular gene expression, inflammatory cytokine release and cell viability. Pretreatment of cells with L-NAC was significantly more effective than pretreatment with the conventional drug in reducing PQ-induced cytotoxicity, as indicated by the biomarkers used in this study. Our results suggested that the delivery of NAC as a liposomal formulation improves its effectiveness in counteracting PQ-induced cytotoxicity.
\end{abstract}

\section{Introduction}

Paraquat $(\mathrm{PQ})$ is a herbicide that preferentially accumulates in the lung and exerts its cytotoxic effects via the generation of reactive oxygen species (ROS) [1-3]. Many studies have focused on increasing the antioxidant status in the lung to protect against PQ injury using various antioxidants, including antioxidant enzymes (e.g., SOD), vitamins (e.g., ascorbic acid, $\alpha$-tocopherol), and low-molecular-weight thiol-containing antioxidants (e.g., glutathione (GSH), Nacetylcysteine (NAC)) but the outcomes from such treatments are limited or without success [2-11]. The failure of these antioxidants to seriously modify the toxicity of the herbicide has been attributed mostly to their inability to cross cell membrane barriers and/or to their rapid clearance from cells $[3,4,6,7,10,11]$. In recent years, it has been demonstrated that the encapsulation of antioxidants in liposomes improves their therapeutic potential against oxidant-induced lung damage, including PQ pulmonary toxicity, because liposomes facilitate intracellular delivery and prolong the retention time of entrapped agents inside the cell $[3,6,12-15]$.

Liposomes are phospholipid vesicles composed of lipid bilayers enclosing an aqueous compartment. Hydrophilic molecules can be encapsulated in the aqueous spaces, and lipophilic molecules can be incorporated into the lipid bilayers. Liposomes, in addition to their use as artificial membrane systems, are used for the selective delivery of antioxidants and other therapeutic drugs to different tissues in sufficient concentrations to be effective in ameliorating tissue injuries. The relative ease in incorporating hydrophilic and lipophilic therapeutic agents into liposomes, the possibility of directly delivering liposomes to an accessible body site, such as the lung, and the relative nonimmunogenicity and low toxicity of liposomes have rendered the liposomal system highly attractive for drug delivery $[3,12,16]$. 
In the present study, we compared the effectiveness of conventional NAC and liposomal-NAC (L-NAC) against PQ-induced cytotoxicity and examined the mechanism(s) by which these antioxidant formulations conferred their cytoprotection. $\mathrm{N}$-Acetylcysteine is a low-molecular-weight thiol-containing antioxidant with free radical-scavenging properties $[3,17,18]$ attributed to the nucleophilicity and redox interactions of its thiol group [17, 18]. Additionally, NAC is a source of cysteine, often the limiting precursor of de novo GSH synthesis $[17,19,20]$. Glutathione is an important antioxidant as it is the most abundant nonprotein thiol present in living cells, and its levels are commonly used as an indicator of intracellular antioxidant status. Furthermore, NAC has been shown to influence redoxsensitive cell-signalling and transcription pathways, such as $\mathrm{NF}-\kappa \mathrm{B}$ (which regulates proinflammatory genes), the $\mathrm{p} 38$, ERK1/2, SAPK/JNK, c-Jun, and c-Fos pathways, among others, in a wide variety of different systems [17, 21, 22]. $\mathrm{N}$-Acetylcysteine has been shown to promote cell growth and survival by activating the MAPK pathway in response to ROS-induced injuries (which normally lead to growth arrest and apoptosis) and is able to limit inflammatory processes, such as the release of proinflammatory cytokines [22]. These actions may play a role in its cytoprotective effect. Accordingly, the cytoprotective effects of NAC or LNAC against PQ-induced cytotoxicity in A549 human lung adenocarcinoma cells were assessed by measuring cellular PQ uptake, intracellular GSH content, ROS levels, mitochondrial membrane potential, cellular gene expression, inflammatory cytokine release, and cell viability. A549 cells possess many important biological properties of the alveolar epithelial type II cell $[23,24]$ and have been shown to be useful for studying the metabolic and macromolecule processing contributions of alveolar type II cells to mechanisms of drug delivery at the pulmonary epithelium [25].

\section{Materials and Methods}

2.1. Cell Culture and Chemicals. Human alveolar type II-like epithelial A549 cells (ATCC no. CCL-185, American Type Culture Collection, Manassas, Va, USA) were maintained in Costar $0.2 \mu \mathrm{m}$ vent cap cell culture flasks (Corning, Corning, NY, USA) with standard Dulbecco's modified Eagle's medium nutrient mixture F-12 Ham (Sigma-Aldrich, St. Louis, Mo, USA) supplemented with 10\% iron-fortified bovine calf serum (SAFC Biosciences, Lenexa, Kan, USA), $2 \mathrm{mM}$ L-glutamine (Gibco, Carlsbad, Calif, USA), and antibiotic/antimycotic $(100 \mathrm{U} / \mathrm{mL}$ penicillin, $100 \mu \mathrm{g} / \mathrm{mL}$ streptomycin, and $0.25 \mu \mathrm{g} / \mathrm{mL}$ amphotericin B; Gibco). Cultures were incubated at $37^{\circ} \mathrm{C}$ in a humidified atmosphere of $5 \%$ $\mathrm{CO}_{2}$ in air and subcultured when $80 \%$ confluent. Prior to plating, cell counts and viabilities were assessed using a Vi-Cell XR Cell Viability Analyzer (Beckman Coulter, Mississauga, ON, Canada). Paraquat (Paraquat dichloride $\mathrm{x}$-hydrate, Sigma-Aldrich) was dissolved in distilled water and diluted with culture media to prepare specific treatment concentrations. Experiments were performed using serumfree media.
To determine the cytotoxicity of NAC alone, cells were treated with control media or media containing different concentrations of NAC ( 0 to $50 \mathrm{mM}$ final NAC concentrations). To determine the effect of NAC or L-NAC on the toxicity of $\mathrm{PQ}$, cells were first pretreated with control, empty liposomes- (EL-) NAC-, or L-NAC-containing media (5.0 $\mathrm{mM}$ for $4 \mathrm{~h}$ ), followed by treatment with control or PQcontaining media.

2.2. N-Acetylcysteine (NAC) Preparation. NAC (N-acetylL-cysteine, SigmaUltra > 99\% TLC; Sigma-Aldrich) was dissolved in PBS and adjusted to $\mathrm{pH} 7.4$ to produce a $0.1 \mathrm{M}$ stock solution. Following filter sterilization $(0.2 \mu \mathrm{m}$ pore-size filters), specific volumes of $\mathrm{N}$-acetylcysteine stock solution were added to culture media for the pretreatment/treatment of cells. NAC stocks were made fresh daily.

2.3. Liposomal-N-Acetylcysteine Preparation. Liposomal-Nacetylcysteine (L-NAC) was prepared from a mixture of DPPC (dipalmitoylphosphatidylcholine) and NAC in a $7: 3$ molar ratio by using a dehydration-rehydration method as described in [13]. Liposomal vesicle size was determined with a Submicron Particle Sizer (Nicomp Model 270) following rehydration and was found to have a mean diameter of $181.5 \pm 19.6 \mathrm{~nm}$. The encapsulation efficiency of NAC by DPPC-liposomes was measured as $18.5 \%$.

2.4. Cell Viability. Cell viability was measured with the MTT (3-(4,5-dimethylthiazol-2-yl)-2,5-diphenyltetrazolium bromide) assay as previously described in [26]. Viabilities of challenged cells were assessed relative to control cells.

2.5. Determination of Intracellular $N A C$ and $P Q$ Concentration with Ultraperformance Liquid Chromatography (UPLC). The intracellular levels of NAC, PQ, and GSH were determined by an ultraperformance liquid chromatographic (UPLC) method using a Waters Acquity system equipped with a binary solvent manager, an automated sample manager, and a photodiode array detector (Waters, Milford, Mss, USA) as described previously by Mitsopoulos and Suntres [26]. Briefly, after each treatment, cells were harvested via trypsinization, washed twice with phosphate-buffered saline (PBS), lysed via sonication (20 s, 100\% amplitude; Sonic Dismembrator Model 500, Fisher Scientific, Pittsburgh, $\mathrm{Pa}$, USA), centrifuged, and then passed through a $0.2 \mu \mathrm{m}$ filter. The ultrafiltrate was injected onto an Acquity UPLC HSS T3 analytical column $(2.1 \mathrm{~mm}$ I.D. $\times 150 \mathrm{~mm}$ length, $1.8 \mu \mathrm{m}$ particles) with a Vanguard $2.1 \mathrm{~mm}$ I.D. $\times 5 \mathrm{~mm}$ length guard column, at $30^{\circ} \mathrm{C}$. The mobile phase consisted of $23 \mathrm{mM}$ ammonium formate $(\mathrm{pH} 3)$ at a flow rate of $0.250 \mathrm{~mL} / \mathrm{min}$. NAC, PQ, and GSH were measured at wavelengths of 200.3, 257.7, and $202.1 \mathrm{~nm}$, respectively, and values were normalized to total protein using the Micro Lowry Total Protein Kit-Peterson's Modification (SigmaAldrich), in accordance with the manufacturer's instructions. 
2.6. Determination of Reactive Oxygen Species Levels. The intracellular levels of reactive oxygen species were determined by staining the cells with $\mathrm{CM}-\mathrm{H}_{2}$ DCFDA (5-(and 6-) chloromethyl-2', 7' -dichlorodihydrofluorescein diacetate, acetyl ester) (Molecular Probes, Eugene, Ore, USA) in PBS as previously described in [26]. Flow cytometric analysis was performed using a BD FACSCalibur Flow Cytometer (BD Biosciences, San Jose, Calif, USA) with BD CellQuest Pro Software. A minimum of 10,000 gated events were acquired per sample.

\subsection{Measurement of Mitochondrial Membrane Potential.} Mitochondrial membrane potential was assessed using the MitoProbe JC-1 Assay Kit for Flow Cytometry (Molecular Probes). Following challenge, cells were washed with PBS and stained for 30 minutes with JC-1 (5,5',6,6' -tetrachloro$1,1^{\prime}, 3,3^{\prime}$-tetraethylbenzimidazolylcarbocyanine iodide), a cationic dye that exhibits potential-dependent accumulation in mitochondria, under standard incubation conditions. Stained cells were detached from the plate surface and suspended in PBS for flow cytometric analysis using the FL1-H and FL2-H channels of a BD FACSCalibur Flow Cytometer (BD Biosciences) with BD CellQuest Pro software. A minimum of 10,000 gated events were acquired per sample. Mitochondrial depolarization was indicated by decreased red fluorescence intensity due to concentration-dependent formation of red fluorescent J-aggregates.

2.8. Gene Expression Analysis. Gene array analysis of cells challenged with $0.25 \mathrm{mM} \mathrm{PQ}$ for $4 \mathrm{~h}$ following pretreatment with control, NAC-containing or L-NAC-containing media $(5.0 \mathrm{mM}$ for $4 \mathrm{~h})$ was performed as detailed previously in [26] using the Human Stress and Toxicity PathwayFinder RT ${ }^{2}$ Profiler PCR Array (Table 1; SA Biosciences).

Conventional RT-PCR analysis of cells challenged as indicated previously was performed using the $\mathrm{RT}^{2}{ }_{\mathrm{qPCR}}$ Primer Assays (Table 2; SA Biosciences). The methodology was carried out similar to that outlined for the gene arrays with the exception that $1 \mu \mathrm{L}$ of the appropriate primer was manually added to each well of the iCycler iQ 96-well PCR Plates (Bio-Rad) and was covered with Microseal "B" Film (Bio-Rad).

2.9. Measurement of Cytokine Levels. Cells seeded into sterile $25 \mathrm{~cm}^{2}$ culture flasks (Corning) at $1.35 \times 10^{6}$ cells/flask were incubated to $80 \%$ confluence overnight, then washed with PBS and pretreated with control, NAC-containing or L-NAC-containing media $(5.0 \mathrm{mM}$ for $4 \mathrm{~h}$ ) followed by challenge with control or PQ-containing media $(0.25$ or $1.0 \mathrm{mM}$ for $4 \mathrm{~h}$ ). Following incubation, media of treated cells were analyzed for cytokine levels using a Human Grp I Cytokine 7-Plex Panel kit (Bio-Rad) specific for interleukin (IL)-1 $\beta$, IL-6, IL-8, IL-10, IL-15, TNF- $\alpha$, and eotaxin, using a Bio-Plex 200 System (Bio-Rad) with Bio-Plex Manager software in accordance with the manufacturer's instructions.
2.10. Statistics. Data are presented as mean \pm S.E.M $(n \geq$ 3 ) and analyzed for statistical significance using the paired Student's $t$-test, with $P<.05$ considered significant. For normalized data, a paired one-sample $t$-test was performed comparing means to a hypothetical mean of $1(P<.05)$.

\section{Results}

3.1. Effect of NAC on Viability of A549 Cells. Challenge of A549 cells with NAC at concentrations ranging from 0 to $10 \mathrm{mM}$ did not have any effect on cell viability $24 \mathrm{~h}$ after NAC exposure. However, a $30 \%$ decrease in viability relative to control cells was observed following treatment with $50.0 \mathrm{mM}$ NAC (Figure 1(a)). A NAC concentration of $5.0 \mathrm{mM}$ was used for all subsequent experiments.

3.2. Uptake of NAC in A549 Cells. The uptake of NAC by A549 cells was assessed using UPLC following treatment with 5.0 mM NAC- or L-NAC-containing media for $0,1,2$, 4,8 , and $24 \mathrm{~h}$ (Figure 1(b)). Treatment of A549 cells with conventional NAC resulted in increased NAC uptake up to $2 \mathrm{~h}$ posttreatment; thereafter, levels remained unchanged up to $24 \mathrm{~h}$ posttreatment. Cells treated with L-NAC exhibited increased uptake over time, with maximal levels achieved following $4 \mathrm{~h}$ treatment. Under all investigated conditions, the uptake of NAC by A549 cells was significantly greater following treatment with the L-NAC formulation compared to NAC.

3.3. Effect of NAC and L-NAC Pretreatment on Cell Viability after PQ Challenge. Challenge of A549 cells with PQ resulted in concentration-dependent decreases in cell viability (Figure 2). Viability of cells challenged with PQ (0.1 and $0.5 \mathrm{mM}$ ) for $24 \mathrm{~h}$ was higher in those cells pretreated with L-NAC. In contrast, pretreatment with NAC or empty liposomes (EL) did not confer any observable effect on cell viability of PQ-challenged cells under these conditions.

\subsection{Effect of NAC and L-NAC Pretreatment on Cellular Redox} Status and PQ Uptake following PQ Challenge. Exposure of cells to increasing concentrations of PQ for $24 \mathrm{~h}$ significantly decreased intracellular GSH content, which correlated with increases in cellular PQ uptake, as measured by UPLC (Figure 3). In general, pretreatment with L-NAC but not NAC resulted in lower PQ-induced depletion in the levels of intracellular GSH content of cells. Pretreatment with NAC or L-NAC had no effect on the linear $\left(R^{2}=0.969\right)$ uptake of PQ in A549 cells challenged with increasing concentrations of PQ (Figure 3(b)). ROS levels increased following PQ exposure (Figure 3(c)), but pretreatment with NAC or LNAC significantly reduced levels of ROS in 0.25 and $1.0 \mathrm{mM}$ PQ-challenged cells $(4 \mathrm{~h})$ to either basal or subbasal levels as assessed via flow cytometric analysis of $\mathrm{CM}-\mathrm{H}_{2}$ DCFDAstained cells (Figure 3(c)).

3.5. Effect of NAC or L-NAC Pretreatment on Mitochondrial Membrane Potential following PQ Challenge. The mitochondrial membrane potential of cells challenged with $0.25 \mathrm{mM}$ 
TABLE 1: Relative expression, via microarray analysis, of genes involved with cellular stress and toxicity in cells challenged with 0.25 mM PQ for $4 \mathrm{~h}$ following pretreatment with control, NAC-containing, or L-NAC-containing media. Genes are listed in order of decreasing fold change in cells pretreated with control media and challenged with PQ. Fold change is expressed relative to untreated control cells using the housekeeping genes B2M, HPRT1, RPL13A, and GAPDH. Note. the proposed housekeeping gene ACTB was significantly altered following PQ challenge, and was not used in this capacity in our study. $n=3$ independent experiments.

\begin{tabular}{|c|c|c|c|c|c|c|c|c|}
\hline \multirow{2}{*}{$\begin{array}{l}\text { GeneBank } \\
\text { accession no. }\end{array}$} & \multirow{2}{*}{ Gene name } & \multirow{2}{*}{ Symbol } & \multicolumn{6}{|c|}{ Fold change } \\
\hline & & & $\begin{array}{l}\text { Control } \\
\text { media } \\
+\mathrm{PQ}\end{array}$ & $P$ value & $\begin{array}{l}\text { NAC } \\
+\mathrm{PQ}\end{array}$ & $P$ value & $\begin{array}{l}\text { LNAC } \\
+\mathrm{PQ}\end{array}$ & $P$ value \\
\hline \multicolumn{9}{|c|}{ Oxidative/metabolic stress } \\
\hline NM_005953 & Metallothionein 2A & MT2A & 1.17 & 0.127 & -1.07 & 0.616 & 1.33 & 0.229 \\
\hline NM_002133 & Heme oxygenase (decycling) 1 & HMOX1 & 1.14 & 0.531 & 1.34 & 0.170 & -1.16 & 0.456 \\
\hline NM_000962 & $\begin{array}{l}\text { Prostaglandin-endoperoxide synthase } 1 \\
\text { (prostaglandin G/H synthase and } \\
\text { cyclooxygenase) }\end{array}$ & PTGS1 & 1.10 & 0.671 & 1.34 & 0.208 & 1.50 & $0.026^{* *}$ \\
\hline NM_001885 & Crystallin, alpha B & CRYAB & 1.07 & 0.847 & 1.36 & 0.190 & 1.18 & 0.510 \\
\hline NM_002574 & Peroxiredoxin 1 & PRDX1 & 1.07 & 0.505 & 1.05 & 0.367 & 1.04 & 0.662 \\
\hline NM_000454 & $\begin{array}{l}\text { Superoxide dismutase 1, soluble } \\
\text { (amyotrophic lateral sclerosis } 1 \text { (adult)) }\end{array}$ & SOD1 & 1.04 & 0.343 & 1.05 & 0.332 & -1.07 & 0.200 \\
\hline NM_000581 & Glutathione peroxidase 1 & GPX1 & 1.01 & 0.812 & 1.05 & 0.395 & -1.08 & 0.286 \\
\hline NM_000849 & Glutathione S-transferase M3 (brain) & GSTM3 & -1.02 & 0.833 & -1.09 & 0.600 & -1.03 & 0.743 \\
\hline NM_001752 & Catalase & CAT & -1.03 & 0.740 & -1.31 & 0.136 & -1.16 & 0.168 \\
\hline NM_000637 & Glutathione reductase & GSR & -1.08 & 0.594 & -1.57 & 0.098 & -1.46 & 0.111 \\
\hline NM_005809 & Peroxiredoxin 2 & PRDX2 & -1.12 & 0.528 & -1.01 & 0.892 & -1.22 & 0.573 \\
\hline NM_001461 & Flavin-containing monooxygenase 5 & FMO5 & -1.28 & 0.154 & -1.53 & 0.072 & -1.60 & 0.065 \\
\hline NM_000499 & $\begin{array}{l}\text { Cytochrome P450, family } 1 \text {, subfamily A, } \\
\text { polypeptide } 1\end{array}$ & CYP1A1 & -1.40 & 0.057 & 1.09 & 0.583 & 4.44 & $0.003^{* *}$ \\
\hline NM_000941 & P450 (cytochrome) oxidoreductase & POR & -1.93 & 0.174 & 1.26 & 0.367 & -2.70 & 0.122 \\
\hline NM_001979 & Epoxide hydrolase 2, cytoplasmic & EPHX2 & -2.06 & 0.066 & -2.24 & 0.225 & -1.22 & 0.369 \\
\hline NM_000773 & $\begin{array}{l}\text { Cytochrome P450, family } 2 \text {, subfamily E, } \\
\text { polypeptide } 1\end{array}$ & CYP2E1 & - & - & - & - & - & - \\
\hline NM_000780 & $\begin{array}{l}\text { Cytochrome P450, family } 7 \text {, subfamily A, } \\
\text { polypeptide } 1\end{array}$ & CYP7A1 & - & - & - & - & - & - \\
\hline NM_002021 & Flavin-containing monooxygenase & FMO1 & - & - & - & - & - & - \\
\hline \multicolumn{9}{|c|}{ Heat shock } \\
\hline NM_005347 & $\begin{array}{l}\text { Heat shock } 70 \mathrm{kDa} \text { protein } 5 \\
\text { (glucose-regulated protein, } 78 \mathrm{kDa} \text { ) }\end{array}$ & HSPA5 & 1.35 & $0.004^{* *}$ & 1.24 & $0.026^{* *}$ & -1.00 & 0.983 \\
\hline NM_007034 & $\begin{array}{l}\text { DnaJ (Hsp40) homolog, subfamily B, } \\
\text { member } 4\end{array}$ & DNAJB4 & 1.32 & 0.052 & 1.10 & 0.568 & -1.02 & 0.813 \\
\hline NM_001539 & $\begin{array}{l}\text { DnaJ (Hsp40) homolog, subfamily A, } \\
\text { member } 1\end{array}$ & DNAJA1 & 1.29 & $0.048^{* *}$ & 1.12 & 0.439 & -1.08 & 0.443 \\
\hline NM_005526 & Heat shock transcription factor 1 & HSF1 & 1.14 & 0.074 & 1.08 & 0.253 & 1.13 & 0.354 \\
\hline NM_006644 & Heat shock $105 \mathrm{kDa} / 110 \mathrm{kDa}$ protein 1 & HSPH1 & 1.14 & 0.253 & 1.03 & 0.551 & 1.03 & 0.612 \\
\hline $\begin{array}{l}\text { NM_001 } \\
040 \\
141\end{array}$ & $\begin{array}{l}\text { Heat shock protein } 90 \mathrm{kDa} \text { alpha (cytosolic), } \\
\text { class A member } 2\end{array}$ & HSP90AA2 & 1.08 & 0.200 & 1.05 & 0.557 & 1.09 & 0.279 \\
\hline NM_002157 & Heat shock $10 \mathrm{kDa}$ protein 1 (chaperonin 10 ) & HSPE1 & 1.07 & 0.414 & -1.06 & 0.367 & -1.07 & 0.503 \\
\hline NM_002156 & Heat shock $60 \mathrm{kDa}$ protein 1 (chaperonin) & HSPD1 & 1.06 & 0.671 & -1.15 & 0.312 & -1.08 & 0.406 \\
\hline NM_006597 & Heat shock $70 \mathrm{kDa}$ protein 8 & HSPA8 & 1.02 & 0.922 & -1.09 & 0.599 & -1.33 & 0.060 \\
\hline NM_021979 & Heat shock $70 \mathrm{kDa}$ protein 2 & HSPA2 & 1.01 & 0.908 & -1.40 & $0.004^{* *}$ & -1.46 & $0.003^{* *}$ \\
\hline NM_002154 & Heat shock $70 \mathrm{kDa}$ protein 4 & HSPA4 & -1.06 & 0.523 & -1.47 & $0.036^{* *}$ & -1.71 & $0.004^{* *}$ \\
\hline NM_007355 & $\begin{array}{l}\text { Heat shock protein } 90 \mathrm{kDa} \text { alpha (cytosolic), } \\
\text { class B member } 1\end{array}$ & HSP90AB1 & -1.07 & 0.666 & 1.00 & 0.995 & -1.61 & 0.058 \\
\hline
\end{tabular}


Table 1: Continued.

\begin{tabular}{|c|c|c|c|c|c|c|c|c|}
\hline \multirow{2}{*}{$\begin{array}{l}\text { GeneBank } \\
\text { accession no. }\end{array}$} & \multirow{2}{*}{ Gene name } & \multirow{2}{*}{ Symbol } & \multicolumn{6}{|c|}{ Fold change } \\
\hline & & & $\begin{array}{l}\text { Control } \\
\text { media } \\
+\mathrm{PQ}\end{array}$ & $P$ value & $\begin{array}{l}\mathrm{NAC} \\
+\mathrm{PQ}\end{array}$ & $P$ value & $\begin{array}{l}\text { LNAC } \\
+\mathrm{PQ}\end{array}$ & $P$ value \\
\hline NM_005345 & Heat shock $70 \mathrm{kDa}$ protein $1 \mathrm{~A}$ & HSPA1A & -1.09 & 0.478 & -1.29 & 0.102 & 1.00 & 0.957 \\
\hline NM_001540 & Heat shock $27 \mathrm{kDa}$ protein 1 & HSPB1 & -1.24 & 0.227 & -1.00 & 0.924 & -1.28 & 0.218 \\
\hline NM_005527 & Heat shock $70 \mathrm{kDa}$ protein 1 -like & HSPA1L & -1.29 & 0.084 & -1.65 & $0.032^{* *}$ & -1.42 & 0.077 \\
\hline NM_002155 & Heat shock $70 \mathrm{kDa}$ protein $6\left(\mathrm{HSP} 0 \mathrm{~B}^{\prime}\right)$ & HSPA6 & - & - & - & - & - & - \\
\hline \multicolumn{9}{|c|}{ Proliferation/carcinogenesis } \\
\hline NM_001964 & Early growth response 1 & EGR1 & 1.97 & $0.039^{* *}$ & 1.70 & 0.117 & -1.24 & 0.395 \\
\hline NM_005190 & Cyclin C & CCNC & 1.30 & 0.226 & 1.02 & 0.995 & 1.18 & 0.561 \\
\hline NM_182649 & Proliferating cell nuclear antigen & PCNA & 1.14 & 0.283 & -1.08 & 0.461 & -1.04 & 0.678 \\
\hline NM_053056 & Cyclin D1 & CCND1 & -1.03 & 0.885 & -1.28 & 0.225 & -1.02 & 0.803 \\
\hline NM_004060 & Cyclin G1 & CCNG1 & -1.05 & 0.410 & -1.02 & 0.316 & 1.07 & 0.435 \\
\hline NM_005225 & E2F transcription factor 1 & $\mathrm{E} 2 \mathrm{~F} 1$ & -1.28 & 0.473 & -1.16 & 0.450 & -1.94 & 0.107 \\
\hline \multicolumn{9}{|c|}{ Growth arrest/senescence } \\
\hline NM_004864 & Growth differentiation factor 15 & GDF15 & 1.91 & $0.000^{* *}$ & 1.96 & $0.003^{* *}$ & 1.37 & $0.045^{* *}$ \\
\hline NM_004083 & DNA-damage-inducible transcript 3 & DDIT3 & 1.87 & $0.000^{* *}$ & 2.17 & $0.000^{* *}$ & 1.46 & $0.020^{* *}$ \\
\hline NM_000389 & $\begin{array}{l}\text { Cyclin-dependent kinase inhibitor 1A (p21, } \\
\text { Cip1) }\end{array}$ & CDKN1A & 1.50 & $0.002^{* *}$ & 1.72 & $0.001^{* *}$ & 1.88 & $0.000^{* *}$ \\
\hline NM_001924 & $\begin{array}{l}\text { Growth arrest and DNA-damage-inducible, } \\
\text { alpha }\end{array}$ & GADD45A & 1.29 & 0.125 & 1.50 & $0.044^{* *}$ & -1.01 & 0.942 \\
\hline NM_002392 & $\begin{array}{l}\text { Mdm2, transformed 3T3 cell double minute } \\
\text { 2, p53-binding protein (mouse) }\end{array}$ & MDM2 & 1.26 & 0.119 & -1.01 & 0.999 & 1.25 & 0.112 \\
\hline NM_000546 & Tumor protein p53 & TP53 & 1.14 & 0.294 & -1.10 & 0.546 & -1.11 & 0.353 \\
\hline NM_002178 & Insulin-like growth factor-binding protein 6 & IGFBP6 & -1.19 & 0.186 & 1.04 & 0.761 & -1.58 & $0.032^{* *}$ \\
\hline \multicolumn{9}{|c|}{ Inflammatory } \\
\hline NM_001562 & $\begin{array}{l}\text { Interleukin } 18 \text { (interferon-gamma-inducing } \\
\text { factor) }\end{array}$ & IL18 & 1.49 & $0.010^{* *}$ & 1.26 & 0.106 & 1.28 & $0.016^{* *}$ \\
\hline NM_000575 & Interleukin 1, alpha & IL1A & 1.47 & 0.085 & 1.18 & 0.481 & 1.88 & $0.020^{* *}$ \\
\hline NM_000602 & $\begin{array}{l}\text { Serpin peptidase inhibitor, clade } \mathrm{E} \text { (nexin, } \\
\text { plasminogen activator inhibitor type } 1 \text { ), } \\
\text { member } 1\end{array}$ & SERPINE1 & 1.38 & $0.035^{* *}$ & 1.34 & 0.096 & 1.01 & 0.976 \\
\hline NM_000595 & $\begin{array}{l}\text { Lymphotoxin alpha (TNF superfamily, } \\
\text { member 1) }\end{array}$ & LTA & 1.22 & 0.458 & 1.38 & 0.141 & -2.19 & 0.060 \\
\hline NM_003998 & $\begin{array}{l}\text { Nuclear factor of kappa light polypeptide } \\
\text { gene enhancer in B cells } 1 \text { (p105) }\end{array}$ & NFKB1 & 1.22 & $0.004^{* *}$ & 1.12 & 0.092 & 1.36 & $0.000^{* *}$ \\
\hline NM_002415 & $\begin{array}{l}\text { Macrophage migration inhibitory factor } \\
\text { (glycosylation-inhibiting factor) }\end{array}$ & MIF & 1.02 & 0.505 & 1.13 & $0.043^{* *}$ & -1.06 & 0.331 \\
\hline NM_000576 & Interleukin 1, beta & IL1B & -1.02 & 0.948 & -1.69 & 0.357 & -1.02 & 0.936 \\
\hline NM_002989 & Chemokine (C-C motif) ligand 21 & CCL21 & - & - & - & - & - & - \\
\hline NM_002983 & Chemokine (C-C motif) ligand 3 & CCL3 & - & - & - & - & - & - \\
\hline NM_002984 & Chemokine (C-C motif) ligand 4 & CCL4 & - & - & - & - & - & - \\
\hline NM_001565 & Chemokine (C-X-C motif) ligand 10 & CXCL10 & - & - & - & - & - & - \\
\hline \multicolumn{9}{|c|}{ DNA damage/repair } \\
\hline NM_000051 & Ataxia telangiectasia mutated & ATM & 1.21 & 0.318 & -1.38 & 0.197 & -1.07 & 0.727 \\
\hline NM_005431 & $\begin{array}{l}\text { X-ray repair complementing defective repair } \\
\text { in Chinese hamster cells } 2\end{array}$ & XRCC2 & 1.19 & 0.125 & -1.26 & 0.261 & 1.10 & 0.303 \\
\hline NM_003362 & Uracil-DNA glycosylase & UNG & 1.11 & 0.315 & -1.01 & 0.882 & -1.01 & 0.890 \\
\hline
\end{tabular}


Table 1: Continued.

\begin{tabular}{|c|c|c|c|c|c|c|c|c|}
\hline \multirow{2}{*}{$\begin{array}{l}\text { GeneBank } \\
\text { accession no. }\end{array}$} & \multirow{2}{*}{ Gene name } & \multirow{2}{*}{ Symbol } & \multicolumn{6}{|c|}{ Fold change } \\
\hline & & & $\begin{array}{l}\text { Control } \\
\text { media } \\
+\mathrm{PQ}\end{array}$ & $P$ value & $\begin{array}{l}\text { NAC } \\
+\mathrm{PQ}\end{array}$ & $P$ value & $\begin{array}{l}\text { LNAC } \\
+ \text { PQ }\end{array}$ & $P$ value \\
\hline NM_000122 & $\begin{array}{l}\text { Excision repair cross-complementing rodent } \\
\text { repair deficiency, complementation group } 3 \\
\text { (xeroderma pigmentosum group B } \\
\text { complementing) }\end{array}$ & ERCC3 & 1.07 & 0.612 & -1.26 & 0.271 & -1.20 & 0.229 \\
\hline NM_005053 & RAD23 homolog A (S. cerevisiae) & RAD23A & 1.04 & 0.764 & -1.00 & 0.956 & -1.23 & 0.265 \\
\hline NM_007194 & CHK2 checkpoint homolog (S. pombe) & CHEK2 & 1.03 & 0.844 & -1.32 & 0.111 & -1.23 & 0.100 \\
\hline NM_001923 & $\begin{array}{l}\text { Damage-specific DNA-binding protein 1, } \\
127 \mathrm{kDa}\end{array}$ & DDB1 & -1.11 & 0.403 & -1.26 & 0.241 & -1.54 & $0.041^{* *}$ \\
\hline NM_001983 & $\begin{array}{l}\text { Excision repair cross-complementing rodent } \\
\text { repair deficiency, complementation group } 1 \\
\text { (includes overlapping antisense sequence) }\end{array}$ & ERCC1 & -1.16 & 0.463 & 1.08 & 0.666 & -1.48 & 0.278 \\
\hline NM_006297 & $\begin{array}{l}\text { X-ray repair complementing defective repair } \\
\text { in Chinese hamster cells } 1\end{array}$ & XRCC1 & -1.25 & 0.235 & -1.29 & 0.226 & -1.64 & 0.071 \\
\hline NM_007120 & $\begin{array}{l}\text { UDP glucuronosyltransferase } 1 \text { family, } \\
\text { polypeptide A4 }\end{array}$ & UGT1A4 & -1.30 & 0.319 & -2.04 & 0.071 & -1.50 & 0.283 \\
\hline \multicolumn{9}{|c|}{ Apoptosis signalling } \\
\hline NM_001230 & $\begin{array}{l}\text { Caspase } 10 \text {, apoptosis-related cysteine } \\
\text { peptidase }\end{array}$ & CASP10 & 1.71 & $0.006^{* *}$ & 1.25 & 0.194 & 1.35 & 0.110 \\
\hline NM_001154 & Annexin A5 & ANXA5 & 1.42 & $0.025^{* *}$ & 1.17 & 0.073 & 1.42 & $0.004^{* *}$ \\
\hline NM_020529 & $\begin{array}{l}\text { Nuclear factor of kappa light polypeptide } \\
\text { gene enhancer in B-cells inhibitor, alpha }\end{array}$ & NFKBIA & 1.20 & 0.097 & 1.35 & $0.014^{* *}$ & 1.47 & $0.017^{* *}$ \\
\hline NM_001228 & $\begin{array}{l}\text { Caspase } 8 \text {, apoptosis-related cysteine } \\
\text { peptidase }\end{array}$ & CASP8 & 1.15 & 0.184 & -1.08 & 0.571 & 1.36 & $0.017^{* *}$ \\
\hline NM_004324 & BCL2-associated X protein & BAX & -1.04 & 0.656 & -1.12 & 0.503 & -1.30 & 0.069 \\
\hline NM_003810 & $\begin{array}{l}\text { Tumor necrosis factor (ligand) superfamily, } \\
\text { member } 10\end{array}$ & TNFSF10 & -1.09 & 0.788 & -1.15 & 0.444 & -1.53 & 0.110 \\
\hline NM_033292 & $\begin{array}{l}\text { Caspase 1, apoptosis-related cysteine } \\
\text { peptidase (interleukin 1, beta, convertase) }\end{array}$ & CASP1 & -1.11 & 0.818 & -1.24 & 0.150 & -1.19 & 0.627 \\
\hline NM_001065 & $\begin{array}{l}\text { Tumor necrosis factor receptor superfamily, } \\
\text { member } 1 \mathrm{~A}\end{array}$ & TNFRSF1A & -1.29 & 0.235 & -1.15 & 0.610 & -1.64 & 0.081 \\
\hline NM_138578 & BCL2-like 1 & BCL2L1 & -1.46 & $0.028^{* *}$ & -1.37 & 0.257 & -1.42 & 0.340 \\
\hline \multicolumn{9}{|c|}{ Housekeeping } \\
\hline NM_001101 & Actin, beta & ACTB & 1.35 & $0.018^{* *}$ & -1.17 & 0.251 & 1.23 & 0.152 \\
\hline NM_004048 & Beta-2-microglobulin & B2M & - & - & - & - & - & - \\
\hline NM_000194 & $\begin{array}{l}\text { Hypoxanthine phosphoribosyltransferase } 1 \\
\text { (Lesch-Nyhan syndrome) }\end{array}$ & HPRT1 & - & - & - & - & - & - \\
\hline NM_012423 & Ribosomal protein L13a & RPL13A & - & - & - & - & - & - \\
\hline NM_002046 & Glyceraldehyde-3-phosphate dehydrogenase & GAPDH & - & - & - & - & - & - \\
\hline
\end{tabular}

PQ for $4 \mathrm{~h}$ was significantly decreased relative to untreated control cells and was further decreased following 1.0 mM PQ challenge. Pretreatment with L-NAC was effective in preventing the decreases of mitochondrial membrane potential in both 0.25 and $1.0 \mathrm{mM}$ PQ-challenged cells, returning it to basal levels in the former, as well as increasing it nearly 2fold when compared to untreated control cells (Figure 4). Conversely, pretreatment with NAC only significantly pre- vented the decrease in mitochondrial membrane potential of $0.25 \mathrm{mM}$ PQ-challenged cells, having no apparent effect on untreated control or 1.0 mM PQ-challenged cells.

3.6. Effect of NAC or L-NAC Pretreatment on the Secretion of Inflammatory Cytokines after PQ Challenge. Levels of IL8 secreted by cells exposed to $0.25 \mathrm{mM}$ and $1.0 \mathrm{mM}$ PQ 
TABLE 2: Relative expression, via conventional RT-PCR analysis, of genes involved with cellular stress and toxicity in cells challenged with $0.25 \mathrm{mM}$ PQ for $4 \mathrm{~h}$ following pretreatment with control on NAC-, L-NAC- or EL-containing media. Fold change is expressed relative to the respective untreated time control using the housekeeping gene RPL13A. $n=3$ independent experiments performed in triplicate.

\begin{tabular}{|c|c|c|c|c|c|c|c|c|c|c|}
\hline \multirow{2}{*}{$\begin{array}{l}\text { GeneBank } \\
\text { accession no. }\end{array}$} & \multirow{2}{*}{ Gene name } & \multirow{2}{*}{ Symbol } & \multicolumn{8}{|c|}{ Fold change } \\
\hline & & & $\begin{array}{l}\text { Control } \\
\text { media } \\
+\mathrm{PQ}\end{array}$ & $P$-value & $\begin{array}{l}\text { NAC } \\
+\mathrm{PQ}\end{array}$ & $P$-value & $\begin{array}{l}\text { LNAC } \\
+ \text { PQ }\end{array}$ & $P$-value & $\begin{array}{c}\mathrm{EL}+ \\
\mathrm{PQ}\end{array}$ & $P$-value \\
\hline \multicolumn{11}{|c|}{ Miscellaneous genes } \\
\hline NM_00584 & Interleukin 8 & IL8 & 2.23 & $0.007^{* *}$ & 2.01 & $0.001^{* *}$ & 1.74 & $0.010^{* *}$ & 2.15 & $0.009^{* *}$ \\
\hline NM_002746 & Mitogen-activated protein kinase 3 & MAPK3 & 1.47 & 0.404 & 1.45 & 0.472 & 1.86 & 0.151 & 1.55 & 0.378 \\
\hline NM_002228 & Jun oncogene & JUN & 1.40 & 0.240 & 1.63 & $0.049^{* *}$ & 1.36 & 0.174 & 1.09 & 0.606 \\
\hline NM_002750 & Mitogen-activated protein kinase 8 & MAPK8 & 1.18 & 0.847 & 1.45 & 0.544 & 1.03 & 0.907 & -1.08 & 0.820 \\
\hline NM_000660 & Transforming growth factor, beta 1 & TGFB1 & 1.13 & 0.593 & 1.34 & 0.245 & 1.26 & 0.316 & 1.07 & 0.664 \\
\hline NM_005252 & $\begin{array}{l}\text { V-fos FBJ murine osteosarcoma viral } \\
\text { oncogene homolog }\end{array}$ & FOS & 1.02 & 0.866 & 1.63 & 0.417 & 1.09 & 0.958 & 1.04 & 0.737 \\
\hline NM_001315 & Mitogen-activated protein kinase 14 & MAPK14 & -1.03 & 0.781 & 1.24 & 0.590 & -1.01 & 0.930 & -1.33 & 0.911 \\
\hline NM_000572 & Interleukin 10 & IL10 & -2.15 & 0.079 & -1.82 & 0.126 & 1.09 & 0.889 & -1.60 & 0.177 \\
\hline \multicolumn{11}{|c|}{ Verification Genes } \\
\hline NM_000576 & Interleukin 1 , beta & IL1B & 1.35 & 0.677 & 1.73 & 0.476 & 1.77 & 0.452 & 1.40 & 0.656 \\
\hline NM_020529 & $\begin{array}{l}\text { Nuclear factor of kappa light } \\
\text { polypeptide gene enhancer in B-cells } \\
\text { inhibitor, alpha }\end{array}$ & NFKBIA & 1.31 & 0.271 & 1.46 & 0.179 & 1.69 & 0.087 & 1.55 & 0.205 \\
\hline NM_000499 & $\begin{array}{l}\text { Cytochrome P450, family } 1 \text {, } \\
\text { subfamily A, polypeptide } 1\end{array}$ & CYP1A1 & 1.12 & 0.950 & 1.10 & 0.925 & 2.26 & 0.155 & 1.77 & 0.400 \\
\hline NM_000575 & Interleukin 1, alpha & IL1A & 1.08 & 0.802 & 1.48 & 0.308 & 1.65 & 0.317 & 1.36 & 0.446 \\
\hline NM_000594 & $\begin{array}{l}\text { Tumor necrosis factor (TNF } \\
\text { superfamily, member } 2 \text { ) }\end{array}$ & TNF & -1.00 & 0.942 & 1.34 & 0.255 & 1.32 & 0.134 & 1.36 & 0.098 \\
\hline NM_000454 & $\begin{array}{l}\text { Superoxide dismutase } 1 \text {, soluble } \\
\text { (amyotrophic lateral sclerosis } 1 \\
\text { (adult)) }\end{array}$ & SOD1 & -1.04 & 0.962 & 1.02 & 0.784 & -1.43 & 0.263 & -1.24 & 0.297 \\
\hline NM_001752 & Catalase & CAT & -1.12 & 0.852 & -1.21 & 0.402 & -1.30 & 0.299 & -1.25 & 0.466 \\
\hline
\end{tabular}

were significantly increased relative to untreated control cells (Figure 5). Both NAC and L-NAC pretreatments decreased IL-8 levels in untreated control cells and $0.25 \mathrm{mM}$ PQchallenged cells, while L-NAC, but not NAC, was also able to significantly reduce levels of IL-8 following $1.0 \mathrm{mM}$ PQ challenge. Levels of IL-1 $\beta$, IL-6, IL-10, IL15, TNF- $\alpha$, and eotaxin were not reliably detectable under these conditions.

\subsection{Effect of NAC or L-NAC Pretreatment on Cellular Gene} Expression following PQ Challenge. Changes in gene expression were assessed using a gene array designed to study genes involved with cellular stress and toxicity. The magnitude of gene expression in cells pretreated with NAC or L-NAC prior to $0.25 \mathrm{mM}$ PQ challenge for $4 \mathrm{~h}$ was generally decreased relative to challenged cells with no pretreatment (Figure 6). Fold changes (relative to control cells) of each gene of the array following PQ challenge with no pretreatment, NAC pretreatment, or L-NAC pretreatment are listed in Table 1.

The expression of many oxidative or metabolic stressrelated genes was not significantly altered under any of the studied conditions, with the exception of CYP1A1 and PTGS1 being significantly upregulated in PQ-challenged cells pretreated with L-NAC. The expression of all studied heat shock genes remained more or less unchanged in PQ-treated cells but HSPA2, HSPA4, and HSPA1L were each significantly downregulated with NAC or L-NAC pretreatment. The expression of EGR1 was increased 2.0-fold in PQ challenged cells in the absence of antioxidant pretreatment but its expression was maintained at control levels with L-NAC pretreatment.

Antioxidant pretreatment of cells subsequently challenged with PQ had an effect on genes related to growth arrest and senescence as well. Briefly, GDF15 and DDIT3 were both significantly upregulated 1.9-fold following PQ challenge and were modulated with L-NAC (1.4- and 1.5-fold, resp.), but not NAC (2.0- and 2.2-fold, resp.), pretreatment. CDKN1A was upregulated 1.5 -fold following PQ challenge and was progressively upregulated further with both NAC (1.7-fold) and L-NAC (1.9-fold) pretreatment. Also significantly altered were the expression patterns of several inflammatory genes. IL18 was upregulated 1.5-fold 


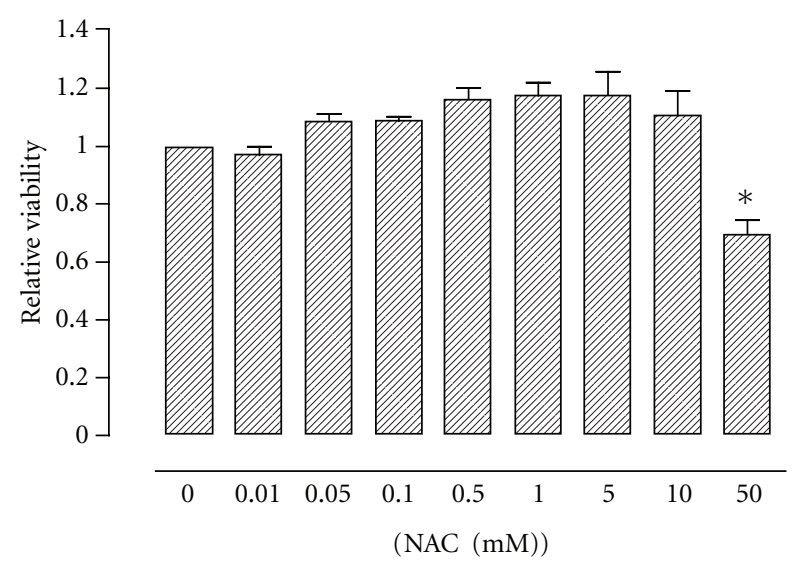

(a)

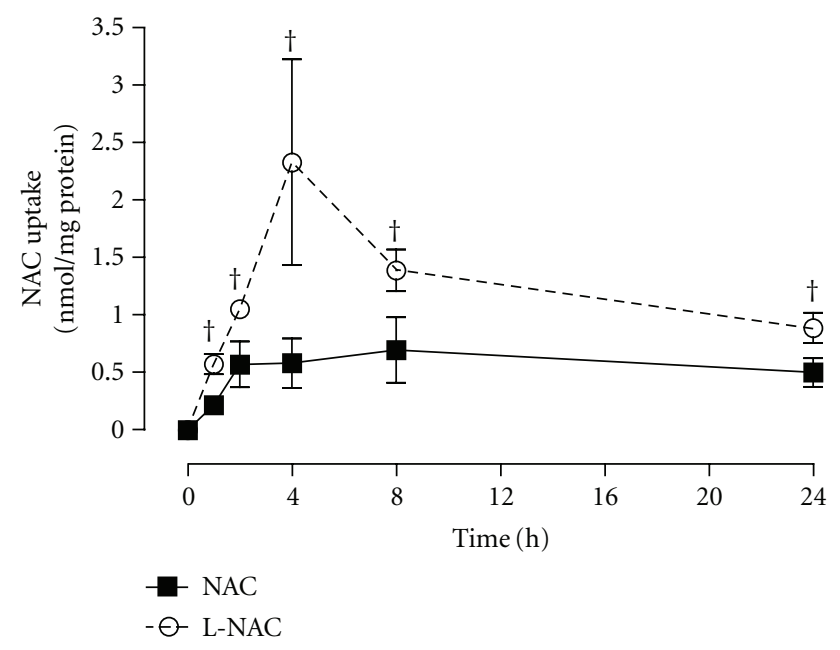

(b)

FIGURE 1: Effect of NAC on the cell viability (a) and uptake of NAC (b) in A549 cells. The viability of cells treated for $24 \mathrm{~h}$ with increasing concentrations of NAC was assessed using the MTT assay. Bars represent mean \pm S.E.M. of 3 independent experiments performed in octuplet. ${ }^{*}$ denotes significant difference relative to control $(P<$ $.05)$. For the uptake studies (b), cells were treated with either 5.0 mM NAC- or L-NAC-containing media for various time-points up to $24 \mathrm{~h}$; intracellular NAC levels were measured with a UPLC method as described in Section 2. (solid line: NAC treatment; dotted line: L-NAC treatment). Data points represent mean \pm S.E.M. of 3 independent experiments performed in duplicate. ${ }^{\dagger}$ denotes significant difference relative to NAC-treated group $(P<.05)$.

in PQ-challenged cells, but its expression was modulated with NAC or L-NAC pretreatment. Using individual primer assays with conventional RT-PCR, we found IL8 to be significantly upregulated (2.2-fold) in PQ-challenged cells with no pretreatment, but it was progressively modulated with NAC (2.0-fold) and L-NAC (1.7-fold) pretreatment. It is worth noting that the IL10 gene, which codes for the antiinflammatory cytokine IL-10, was down-regulated in PQchallenged cells, an effect reversed by L-NAC, but not NAC, pretreatment. Finally, the expression of many apoptosis signalling genes was not altered under the studied conditions

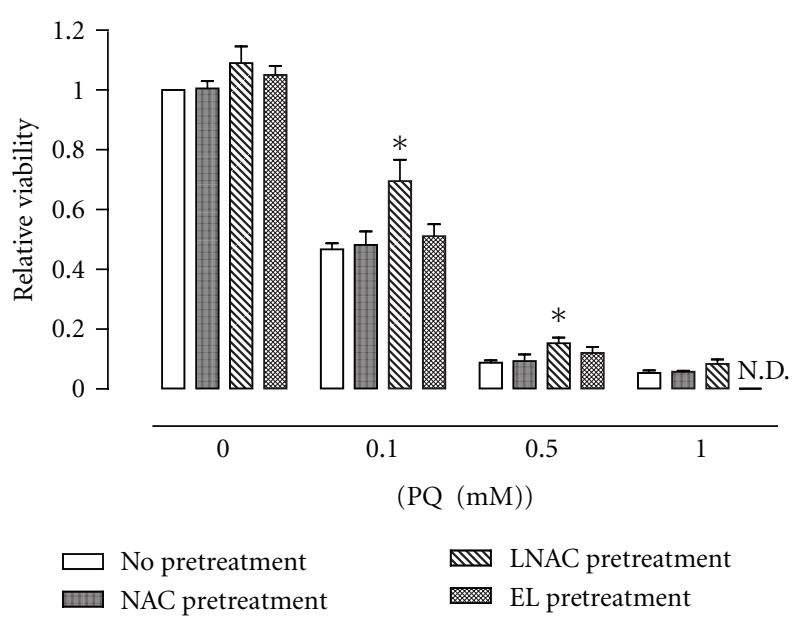

Figure 2: Effect of EL, NAC, or L-NAC pretreatment on viability of PQ-challenged cells. The viability of cells pretreated with control media (no pretreatment), or 5.0 mM NAC- (NAC Pretreatment), LNAC- (L-NAC pretreatment) or empty liposome-containing media (EL pretreatment) for $4 \mathrm{~h}$ prior to $24 \mathrm{~h} P Q$ challenge $(0,0.1,0.5$, or $1.0 \mathrm{mM}$ ) was assessed using the MTT assay. Bars represent mean \pm S.E.M. of 3 independent experiments performed in octuplet. * denotes significant difference relative to cells with no pretreatment $(P<.05)$; N.D.: not determined.

with the exception of CASP10, which was upregulated 1.7-fold in PQ-challenged cells with no pretreatment and was modulated by both NAC and L-NAC pretreatment. The effect of L-NAC was confirmed to not be a direct result of the lipids composing the liposomes as pretreatment with empty liposomes did not alter the expression compared to PQ-challenged cells with no pretreatment (Table 2).

Conventional RT-PCR assays were performed to validate findings obtained from the gene arrays. Similar gene expression patterns were observed for the majority of the genes (e.g., CAT, CYP1A1, IL1A, NFKBIA, and SOD1) analyzed by both methods.

3.8. Validation of Gene Array Data Using Conventional RT$P C R$. Figure 7 depicts a representative electropherogram of extracted RNA, achieved using the Experion automated electrophoresis station, indicating high RNA integrity with little or no apparent degradation of 18 and $28 \mathrm{~S}$ rRNA. Additionally, a single peak (or zero if no product was amplified) was present in first-derivative dissociation curves for every PCR reaction on all gene arrays and conventional RT-PCR assays, indicating that only a single PCR product (i.e., the gene of interest) was amplified in each case.

3.9. Effects of Empty Liposomes on Cytotoxicity and Gene Array Analysis. Challenge of A549 cells with empty liposomes was not toxic to cells. Also, pretreatment of cells with empty liposomes did not confer any protection against PQ-induced cytotoxicity (Figure 2) and gene array analysis (Table 2). 


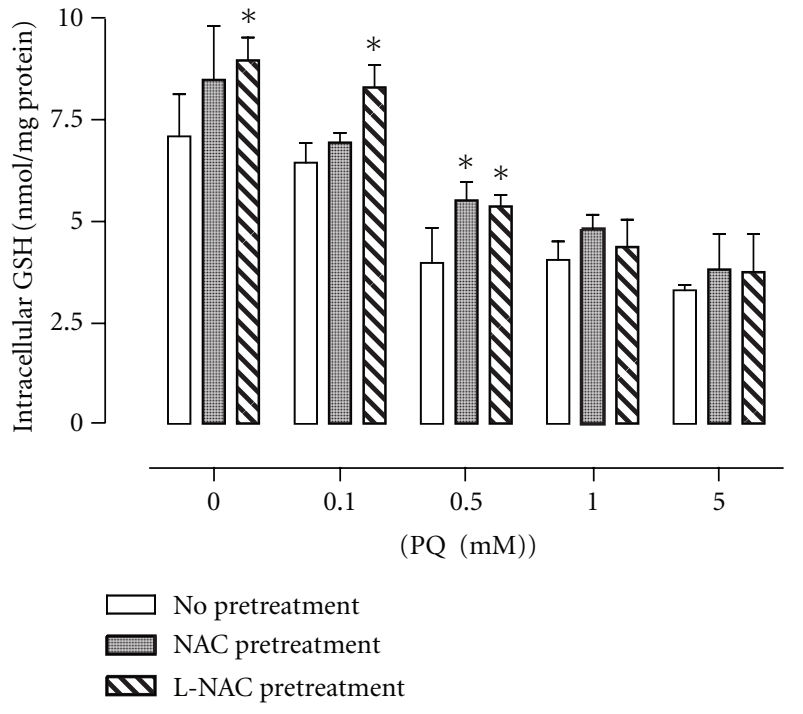

(a)

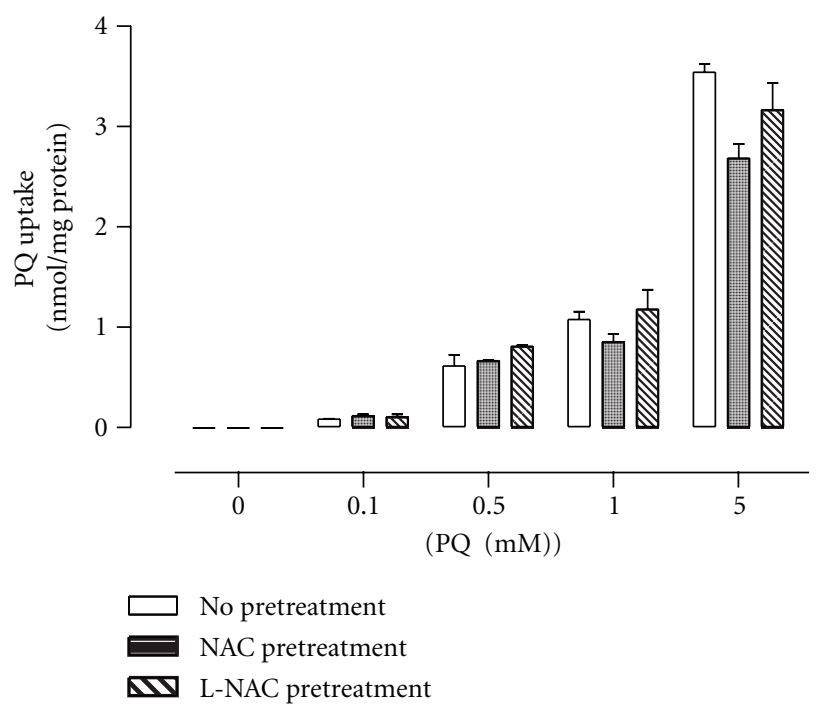

(b)

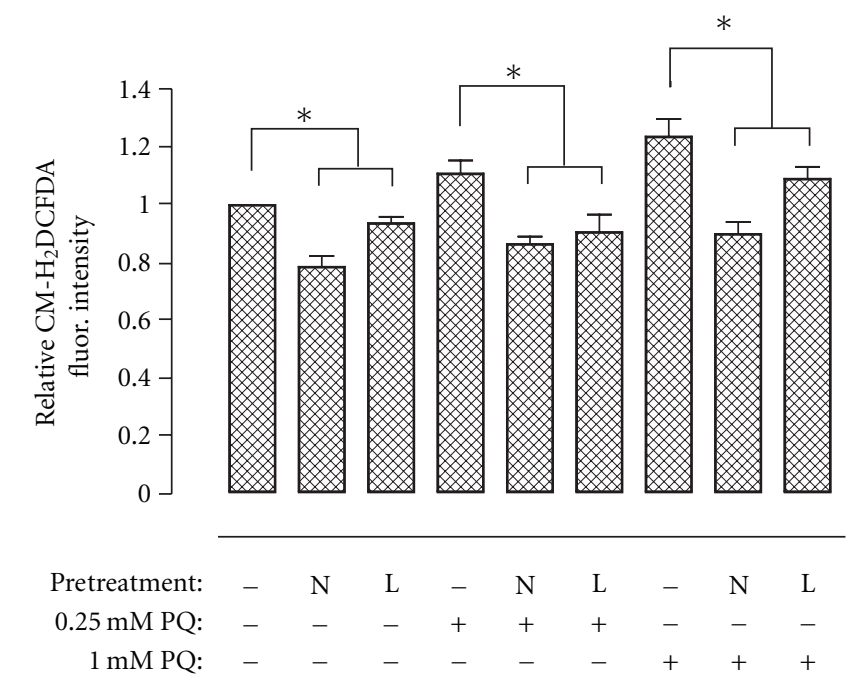

(c)

FIGURE 3: Effect of NAC or L-NAC pretreatment on intracellular levels of GSH (a), PQ (b), and ROS (c) in PQ-challenged cells. Cells pretreated for $4 \mathrm{~h}$ with control media (No Pretreatment) or $5.0 \mathrm{mM}$ NAC- (NAC Pretreatment) or L-NAC-containing media (L-NAC Pretreatment) were challenged with increasing PQ concentrations $(0,0.1,0.5,1.0$, and $5.0 \mathrm{mM})$ for 24 h. Cells were harvested and lysed for concomitant measurement of intracellular GSH content (a) and PQ uptake (b) via UPLC analysis and normalized to total protein. For the measurement of ROS, cells were stained for $30 \mathrm{~min}$ posttreatment with the cell permeable $\mathrm{CM}_{-} \mathrm{H}_{2}$ DCFDA fluorescent dye specific for oxidative species. Adherent cells were scraped and analyzed flow cytometrically using the FL1-H channel. Bars represent mean \pm S.E.M. of 3 independent experiments. ${ }^{*}$ denotes significant difference relative to cells with no pretreatment $(P<.05)$.

\section{Discussion}

The results of the present study showed that exposure of A549 cells to PQ in vitro resulted in a concentration- and time-dependent accumulation of PQ which was associated with concomitant increases in the intracellular levels of ROS and decreases in GSH levels, confirming results from other studies that PQ exerts its toxic effects, to a major extent, via oxidative stress mechanisms $[1-3,26]$. Accordingly, research efforts in the management of PQ poisoning are also directed towards the use of antioxidants. A potential antioxidant candidate is NAC because not only it is available in the clinic but also its thiol group provides free radical-scavenging properties and it acts as a source of cysteine, often the limiting precursor of de novo GSH synthesis $[3,17,18]$.

In order to assess the cytoprotective effects of both the conventional and liposomal NAC formulations, we first investigated their optimal treatment conditions in A549 cells. NAC has been reported to exhibit cytotoxicity at variable concentrations depending on cell type: $10 \mathrm{mM}$ NAC was 


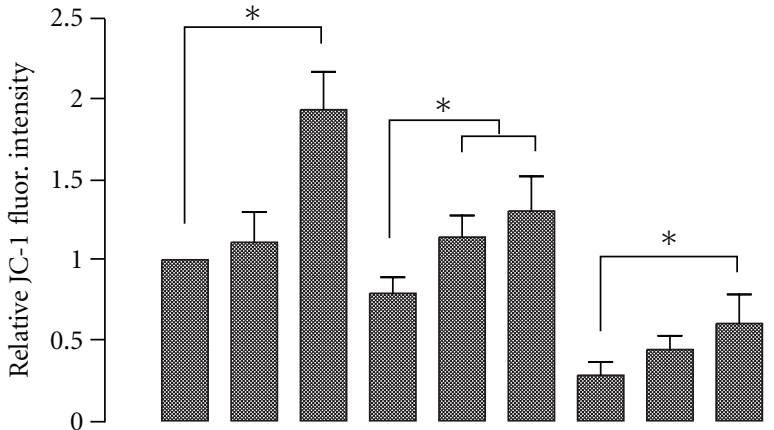

$\begin{array}{rlllllllll}\text { Pretreatment: } & - & \mathrm{N} & \mathrm{L} & - & \mathrm{N} & \mathrm{L} & - & \mathrm{N} & \mathrm{L} \\ 0.25 \mathrm{mM} \text { PQ: } & - & - & - & + & + & + & - & - & - \\ 1 \mathrm{mM} \text { PQ: } & - & - & - & - & - & - & + & + & +\end{array}$

FIGURE 4: Effect of NAC or L-NAC pretreatment on mitochondrial membrane potential following PQ challenge. Cells pretreated for $4 \mathrm{~h}$ with control media or 5.0 mM NAC- $(\mathrm{N})$ or L-NAC-containing media (L) were challenged with $0,0.25$, or $1.0 \mathrm{mM}$ PQ for $4 \mathrm{~h}$. Cells were stained for $30 \mathrm{~min}$ posttreatment with the cell permeable JC1 fluorescent dye. Bars represent mean \pm S.E.M. of 3 independent experiments. ${ }^{*}$ denotes significant difference relative to cells with no pretreatment $(P<.05)$.

nontoxic in human bronchial epithelial cells [17], $40 \mathrm{mM}$ was nontoxic in 3T3 fibroblasts [27], and $50 \mathrm{mM}$ was nontoxic in aortic endothelial cells [17]; however, $30 \mathrm{mM}$ was cytotoxic in vascular smooth muscle cells, monocytes, and neutrophils, and as low as $5.0 \mathrm{mM}$ NAC was cytotoxic in porcine aortic endothelial cells [17]. Studies involving NAC in A549 cells have generally employed concentrations ranging from 1 to $10 \mathrm{mM}[26,28-31]$. Our results indicate that concentrations of $10.0 \mathrm{mM}$ or less had no negative impact on cell viability, while a greater concentration (i.e., $50.0 \mathrm{mM}$ ) resulted in significantly decreased cell viability after $24 \mathrm{~h}$ (Figure 1).

Both NAC formulations conferred protection against PQ-induced cytotoxicity but generally L-NAC was more effective than the conventional NAC formulation in limiting the PQ-induced decreases of cellular GSH content (Figure $3(\mathrm{a})$ ) and production of ROS (Figure 3(c)). The protective effect of NAC or L-NAC cannot be attributed to the effect of the antioxidant formulations on PQ uptake since NAC or L-NAC pretreatment had no effect on intracellular PQ levels in A549 cells (Figure 3(b)). It is unclear whether this protective effect is a result of NAC's direct scavenging properties or the de novo synthesis of GSH using NAC as a precursor. The possible reason for the protective effects being more prominent in cells pretreated with L-NAC was the greater and more sustainable intracellular NAC levels that can be achieved via liposomal delivery (Figure 1(b)). Cellular uptake experiments showed that the uptake of NAC as a liposomal formulation was much greater (i.e., up to 4-fold) under all conditions studied when delivered as LNAC compared to NAC (Figure 1(b)). Thus, the higher and more sustained intracellular NAC levels are responsible for maintaining a normal cellular redox status as evidenced

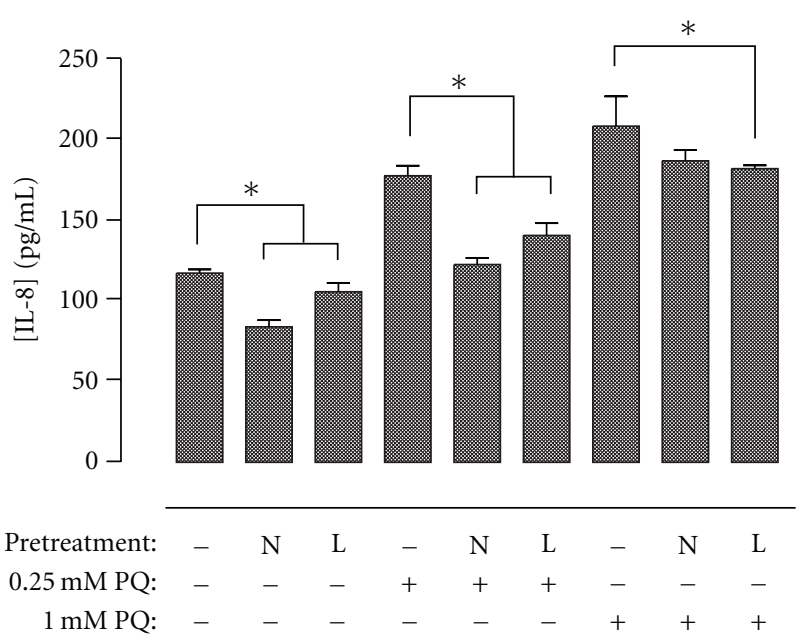

FIGURE 5: Effect of NAC or L-NAC pretreatment on IL-8 levels after PQ exposure. Cells pretreated for $4 \mathrm{~h}$ with control media or $5.0 \mathrm{mM}$ NAC- $(\mathrm{N})$ or L-NAC-containing media (L) were challenged with 0 , 0.25 , or $1.0 \mathrm{mM}$ PQ for $4 \mathrm{~h}$. Cell culture supernatants were collected immediately following challenge and concomitantly analyzed for IL-8 using the Bio-Plex suspension array system. Bars represent mean \pm S.E.M. of 3 independent experiments. ${ }^{*}$ denotes significant difference relative to cells with no pretreatment $(P<.05)$.

by the reduced production of ROS and higher GSH levels. It should be noted that pretreatment of cells with empty liposomes consisting of DPPC lipids did not alter the PQinduced changes in cytotoxicity and gene expression.

The mitochondria are thought to be essential targets of PQ and important in its toxicity. In fact, there is evidence that PQ disrupts the mitochondrial electron transfer chain resulting in a reduction of metabolic function, and it is suggested that lesions due to $\mathrm{PQ}$ first occur in the mitochondria [32-34]. Pretreatment with NAC or L-NAC exhibited a beneficial effect on the mitochondrial membrane potential of PQ-challenged cells (Figure 4). NAC or LNAC pretreatment increased the membrane potential above control levels in $0.25 \mathrm{mM}$ PQ-challenged cells for $4 \mathrm{~h}$, while L-NAC, but not NAC, pretreatment limited the decrease of membrane potential in cells exposed to $1.0 \mathrm{mM} P Q$. Interestingly, control cells pretreated with L-NAC exhibited nearly a 2 -fold increase in fluorescence intensity relative to control cells with no pretreatment. Suntres et al. [8] have shown that radioactively-labelled liposomal antioxidant vesicles were associated with mitochondria, and antioxidants that are selectively accumulated into mitochondria can inhibit mitochondrial oxidative damage that contributes to a range of degenerative diseases related to oxidative stress.

The maintenance of cellular redox status is crucial for cellular homeostasis, and its dysregulation towards a more oxidized intracellular environment is associated with aberrant transcriptional activation and gene expression affecting several processes such as cell growth, differentiation, and inflammation [22, 35-37]. In this study, the magnitude of PQ-induced changes in gene expression in cells pretreated with NAC or L-NAC prior to $0.25 \mathrm{mM}$ PQ challenge for 


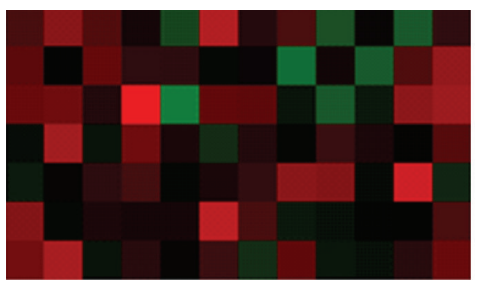

No pretreatment

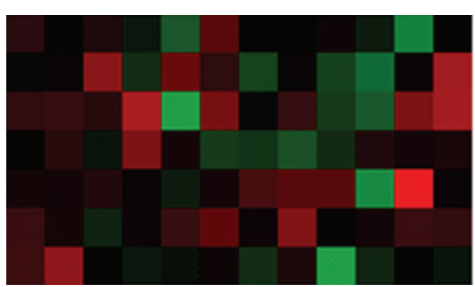

NAC pretreatment

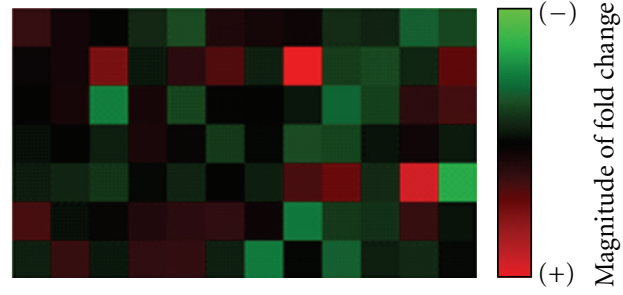

L-NAC pretreatment

FIGURE 6: Effect of NAC or L-NAC pretreatment on the magnitude of gene expression in PQ-challenged cells. RNA was extracted from cells challenged with 0 or $0.25 \mathrm{mM}$ PQ for $4 \mathrm{~h}$ following pretreatment with $5.0 \mathrm{mM} \mathrm{NAC}$ - or L-NAC-containing media and analyzed via quantitative reverse-transcription PCR using a gene array. The magnitude of expression of each gene is expressed on a scale ranging from minimal (intense green) to maximal (intense red) expression ( $n=3$ independent experiments).

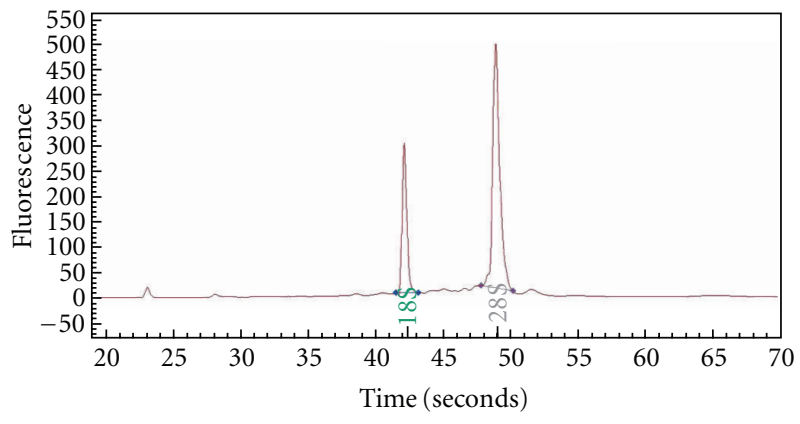

(a)

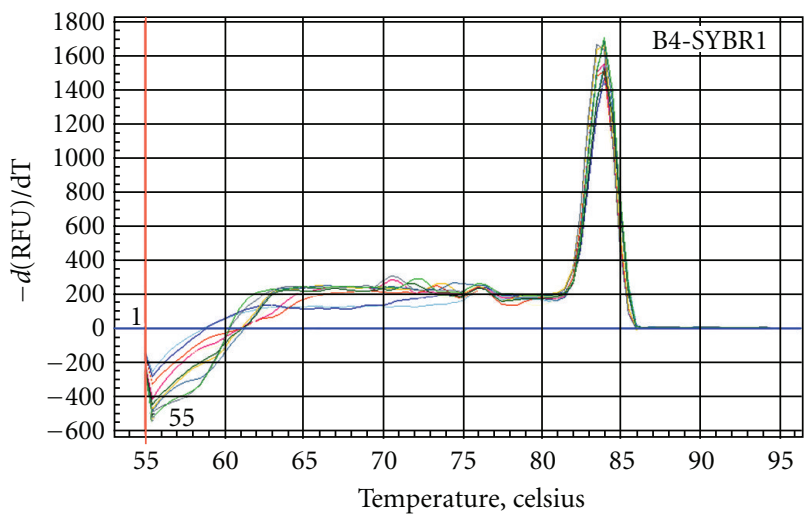

(b)

FIgURE 7: Validation of RNA integrity (a) and assessment of PCR gene product quality (b). Aliquots of extracted RNA from control or PQ-challenged A549 cells with or without pretreatment were assessed for RNA concentration and integrity using the Experion automated electrophoresis station. A representative electropherogram displays 18 and $28 \mathrm{~S}$ rRNA peaks. Representative first-derivative dissociation curves of amplified PCR product of $4 \mathrm{~h}$ control and PQ-challenged cells pretreated with control media or NAC- or L-NAC-containing media are depicted.

$4 \mathrm{~h}$ was generally lower with the L-NAC being a more effective treatment than NAC (Figure 6). Although the exact mechanism(s) by which NAC affected the pathways involved in signal transduction and gene expression cannot be delineated from the results of this study, it is possible that these pathways are regulated by oxidants and redox-sensitive steps since increasing levels of intracellular NAC affect the steady state level of oxidants (Figure 3(c)) and can modify the redox status of the cell (Figure 3), an effect known to exert a regulatory effect on transcriptional activation and gene expression [22, 35, 38-40]. For example, expression of GDF15, IL8, EGR1, and CASP10 genes is known to be upregulated in oxidative stress-induced conditions, a treatment effect counteracted by the presence of antioxidants $[36,41-47]$. The upregulation of GDF15, a protein that plays a role in regulating inflammatory and apoptotic pathways in injured tissues and during disease processes [48-50], and EGR1, which encodes a transcriptional regulator that activates genes (including p53) required for differentiation and mitogenesis [51], was maintained closer to normal levels in cells pretreated with L-NAC, but not NAC (Table 1). The expression of CASP10, which codes for the initiator caspase10 involved in the death-inducing signaling complex during apoptosis (Bidere et al. [52]), was upregulated 1.7-fold in PQ-challenged cells but was closer to control levels in PQchallenged cells pretreated with NAC or L-NAC (Table 1). It is evident that the preservation of cellular homeostasis by L-NAC, and to a lesser extent by NAC, promoted cell survival.

Paraquat administration has been shown to be associated with an infiltration of neutrophils in lung $[5,53]$. Interleukin-8 (IL-8), a potent proinflammatory cytokine released in response to injury, has a key role in the recruitment and activation of neutrophils during inflammation $[54,55]$. The expression of IL8 gene was upregulated in PQchallenged cells, but its expression was substantially modulated with pretreatment of L-NAC and to a lesser extent with NAC (Table 2). The inhibitory effects of NAC and L-NAC on IL-8 expression were correlated with comparable changes in IL-8 protein secretion in the cell culture supernatant of PQchallenged cells (Figure 5). The ability of NAC to modulate the upregulation of IL- 8 has been described in other studies as well: the increased IL-8 gene [56] and protein $[57,58]$ expression of PQ-challenged peripheral blood mononuclear cells was blocked by NAC [57], and NAC administration was found to inhibit the release of chemotactic factors for neutrophils and consequently reduce their infiltration into the lungs of PQ-challenged rats [9]. 
Oxidative stress, which occurs when the redox homeostasis within the cell is altered, is a key pleiotropic modulator which may be involved in the upregulation and/or downregulation of several genes [35, 37]. IL10, which codes for the anti-inflammatory cytokine interleukin-10 (IL-10), is down-regulated 2.2-fold following PQ-treatment (Table 2 ), suggesting that the cell may be actively repressing anti-inflammatory mediators in favor of proinflammatory mediators (e.g., IL-8). The ability of NAC to prevent the downregulation of IL-10, being greater in cells pretreated with L-NAC than NAC, is an evidence to confirm that the higher intracellular levels of NAC maintain the redox status of cells closer to normalcy.

In conclusion, the results of the present study suggest that pretreatment of A549 cells with NAC, both in its conventional and liposomal form, conferred cytoprotection against PQ-induced toxicity. This was mainly attributed to its ability to ameliorate cellular redox status (i.e., intracellular GSH content and ROS levels) and was independent of PQ uptake. These protective effects were more evident in cells pretreated with L-NAC, which is attributed, at least in part, to the increased NAC levels achieved via liposomal delivery.

\section{Conflict of Interests}

The authors declare that there is no conflict of interest.

\section{Acknowledgment}

This work was supported by a Grant from the Natural Sciences and Engineering Research Council of Canada (NSERC no. 312533-2008).

\section{References}

[1] J. S. Bus and J. E. Gibson, "Paraquat: model for oxidantinitiated toxicity," Environmental Health Perspectives, vol. 55, pp. 37-46, 1984.

[2] L. L. Smith, "The toxicity of paraquat," Adverse Drug Reactions and Acute Poisoning Review, vol. 7, no. 1, pp. 1-17, 1988.

[3] Z. E. Suntres, "Role of antioxidants in paraquat toxicity," Toxicology, vol. 180, no. 1, pp. 65-77, 2002.

[4] E. R. Block, "Potentiation of acute paraquat toxicity by vitamin E deficiency," Lung, vol. 156, no. 3, pp. 195-203, 1979.

[5] Z. E. Suntres and P. N. Shek, "Intratracheally administered liposomal alpha-tocopherol protects the lung against longterm toxic effects of paraquat," Biomedical and Environmental Sciences, vol. 8, no. 4, pp. 289-300, 1995.

[6] Z. E. Suntres and P. N. Shek, "Alleviation of paraquat-induced lung injury by pretreatment with bifunctional liposomes containing $\alpha$-tocopherol and glutathione," Biochemical Pharmacology, vol. 52, no. 10, pp. 1515-1520, 1996.

[7] T. Yasaka, K. Okudaira, and H. Fujito, "Further studies of lipid peroxidation in human paraquat poisoning," Archives of Internal Medicine, vol. 146, no. 4, pp. 681-685, 1986.

[8] Z. E. Suntres, S. R. Hepworth, and P. N. Shek, "Protective effect of liposome-associated $\alpha$-tocopherol against paraquatinduced acute lung toxicity," Biochemical Pharmacology, vol. 44, no. 9, pp. 1811-1818, 1992.
[9] E. Hoffer, I. Avidor, O. Benjaminov et al., "N-acetylcysteine delays the infiltration of inflammatory cells into the lungs of paraquat-intoxicated rats," Toxicology and Applied Pharmacology, vol. 120, no. 1, pp. 8-12, 1993.

[10] E. Hoffer, Y. Baum, A. Tabak, and U. Taitelman, "Nacetylcysteine increases the glutathione content and protects rat alveolar type II cells against paraquat-induced cytotoxicity," Toxicology Letters, vol. 84, no. 1, pp. 7-12, 1996.

[11] S. A. Kang, Y. J. Jang, and H. Park, "In vivo dual effects of vitamin $C$ on paraquat-induced lung damage: dependence on released metals from the damaged tissue," Free Radical Research, vol. 28, no. 1, pp. 93-107, 1998.

[12] W. L. Stone and M. Smith, "Therapeutic uses of antioxidant liposomes," Molecular Biotechnology, vol. 27, no. 3, pp. 217230, 2004.

[13] P. Mitsopoulos, A. Omri, M. Alipour, N. Vermeulen, M. G. Smith, and Z. E. Suntres, "Effectiveness of liposomal-Nacetylcysteine against LPS-induced lung injuries in rodents," International Journal of Pharmaceutics, vol. 363, no. 1-2, pp. 106-111, 2008.

[14] L. M. Hoesel, M. A. Flierl, A. D. Niederbichler et al., "Ability of antioxidant liposomes to prevent acute and progressive pulmonary injury," Antioxidants \& Redox Signaling, vol. 10, no. 5, pp. 973-981, 2008.

[15] Z. E. Suntres and P. N. Shek, "The pulmonary uptake of intravenously administered liposomal $\alpha$-tocopherol is augmented in acute lung injury," Journal of Drug Targeting, vol. 4, no. 3, pp. 151-159, 1996.

[16] M. M. Bailey and C. J. Berkland, "Nanoparticle formulations in pulmonary drug delivery," Medicinal Research Reviews, vol. 29, no. 1, pp. 196-212, 2009.

[17] A. M. Sadowska, B. Manuel-y-Keenoy, and W. A. De Backer, "Antioxidant and anti-inflammatory efficacy of NAC in the treatment of COPD: discordant in vitro and in vivo doseeffects: a review," Pulmonary Pharmacology \& Therapeutics, vol. 20, no. 1, pp. 9-22, 2007.

[18] K. R. Atkuri, J. J. Mantovani, L. A. Herzenberg, and L. A. Herzenberg, "N-acetylcysteine-a safe antidote for cysteine/glutathione deficiency," Current Opinion in Pharmacology, vol. 7, no. 4, pp. 355-359, 2007.

[19] G. S. Kelly, "Clinical applications of N-acetylcysteine," Alternative Medicine Review, vol. 3, no. 2, pp. 114-127, 1998.

[20] M. C. G. van de Poll, C. H. C. Dejong, and P. B. Soeters, "Adequate range for sulfur-containing amino acids and biomarkers for their excess: lessons from enteral and parenteral nutrition," Journal of Nutrition, vol. 136, no. 6, pp. 1694S-1700S, 2006.

[21] F. Pajonk, K. Riess, A. Sommer, and W. H. McBride, "N-acetylL-cysteine inhibits $26 \mathrm{~S}$ proteasome function: implications for effects on NF- $\kappa \mathrm{B}$ activation," Free Radical Biology and Medicine, vol. 32, no. 6, pp. 536-543, 2002.

[22] M. Zafarullah, W. Q. Li, J. Sylvester, and M. Ahmad, "Molecular mechanisms of N-acetylcysteine actions," Cellular and Molecular Life Sciences, vol. 60, no. 1, pp. 6-20, 2003.

[23] D. L. Shapiro, L. L. Nardone, and S. A. Rooney, "Phospholipid biosynthesis and secretion by a cell line (A549) which resembles type II alveolar epithelial cells," Biochimica et Biophysica Acta, vol. 530, no. 2, pp. 197-207, 1978.

[24] L. L. Nardone and S. B. Andrews, "Cell line A549 as a model of Ia. type II pneumocyte. Phospholipid biosynthesis from native and organometallic precursors," Biochimica et Biophysica Acta, vol. 573, no. 2, pp. 276-295, 1979. 
[25] K. A. Foster, C. G. Oster, M. M. Mayer, M. L. Avery, and K. L. Audus, "Characterization of the A549 cell line as a type II pulmonary epithelial cell model for drug metabolism," Experimental Cell Research, vol. 243, no. 2, pp. 359-366, 1998.

[26] P. Mitsopoulos and Z. E. Suntres, "Cytotoxicity and gene array analysis of alveolar epithelial A549 cells exposed to paraquat," Chemico-Biological Interactions, vol. 188, no. 3, pp. 427-436, 2010.

[27] S. Y. Hong, J. O. Yang, E. Y. Lee, and Z. W. Lee, "Effects of $\mathrm{n}$-acetyl-L-cysteine and glutathione on antioxidant status of human serum and 3T3 fibroblasts," Journal of Korean Medical Science, vol. 18, no. 5, pp. 649-654, 2003.

[28] J. Alexandre, F. Batteux, C. Nicco et al., "Accumulation of hydrogen peroxide is an early and crucial step for paclitaxelinduced cancer cell death both in vitro and in vivo," International Journal of Cancer, vol. 119, no. 1, pp. 41-48, 2006.

[29] G. H. Chen, J. L. Lin, and Y. K. Huang, "Combined methylprednisolone and dexamethasone therapy for paraquat poisoning," Critical Care Medicine, vol. 30, no. 11, pp. 25842587, 2002.

[30] A. Rogalska, A. Koceva-Chyła, and Z. Jóźwiak, "Aclarubicininduced ROS generation and collapse of mitochondrial membrane potential in human cancer cell lines," ChemicoBiological Interactions, vol. 176, no. 1, pp. 58-70, 2008.

[31] G. Cappelletti, M. G. Maggioni, and R. Maci, "Apoptosis in human lung epithelial cells: triggering by paraquat and modulation by antioxidants," Cell Biology International, vol. 22, no. 9-10, pp. 671-678, 1998.

[32] S. Snchez, R. P. Aguilar, S. Genta, M. Aybar, E. Villecco, and A. S. Riera, "Role of heat shock protein 60 (HSP60) on paraquat intoxication," Journal of Applied Toxicology, vol. 21, no. 5, pp. 425-430, 2001.

[33] H. M. Cochemé and M. P. Murphy, "The uptake and interactions of the redox cycler paraquat with mitochondria," in Methods in Enzymology, S. A. William and E. S. Immo, Eds., chapter 22, pp. 395-417, Academic Press, New York, NY, USA, 2009.

[34] A. Kaetsu, T. Fukushima, S. Inoue, H. Lim, and M. Moriyama, "Role of heat shock protein 60 (HSP60) on paraquat intoxication," Journal of Applied Toxicology, vol. 21, no. 5, pp. 425-430, 2001.

[35] Y. Morel and R. Barouki, "Repression of gene expression by oxidative stress," Biochemical Journal, vol. 342, no. 3, pp. 481496, 1999.

[36] C. D. Klaassen and S. A. Reisman, "Nrf2 the rescue: effects of the antioxidative/electrophilic response on the liver," Toxicology and Applied Pharmacology, vol. 244, no. 1, pp. 57-65, 2010.

[37] T. Parasassi, R. Brunelli, G. Costa et al., "Thiol redox transitions in cell signaling: a lesson from $\mathrm{N}$-acetylcysteine," The Scientific World Journal, vol. 10, pp. 1192-1202, 2010.

[38] C. Garcia-Ruiz and J. C. Fernández-Checa, "Redox regulation of hepatocyte apoptosis," Journal of Gastroenterology and Hepatology, vol. 22, no. 1, pp. S38-S42, 2007.

[39] T. Parasassi, R. Brunelli, G. Costa et al., "Thiol redox transitions in cell signaling: a lesson from $\mathrm{N}$-acetylcysteine," The Scientific World Journal, vol. 10, pp. 1192-1202, 2010.

[40] O. N. Oktyabrsky and G. V. Smirnova, "Redox regulation of cellular functions," Biochemistry, vol. 72, no. 2, pp. 132-145, 2007.
[41] T. Dandrea, H. Hellmold, C. Jonsson et al., "The transcriptosomal response of human A549 lung cells to a hydrogen peroxide-generating system: relationship to DNA damage, cell cycle arrest, and caspase activation," Free Radical Biology and Medicine, vol. 36, no. 7, pp. 881-896, 2004.

[42] J. M. Lai, J. T. Chang, C. L. Wen, and S. L. Hsu, "Emodin induces a reactive oxygen species-dependent and ATM-p53Bax mediated cytotoxicity in lung cancer cells," European Journal of Pharmacology, vol. 623, no. 1-3, pp. 1-9, 2009.

[43] S. Wu, J. Gao, Q. T. Dinh, C. Chen, and S. Fimmel, "IL8 production and AP-1 transactivation induced by UVA in human keratinocytes: roles of d- $\alpha$-tocopherol," Molecular Immunology, vol. 45, no. 8, pp. 2288-2296, 2008.

[44] J. Maher and M. Yamamoto, "The rise of antioxidant signaling-the evolution and hormetic actions of Nrf2," Toxicology and Applied Pharmacology, vol. 244, no. 1, pp. 415, 2010.

[45] T. Kurita-Ochiai and K. Ochiai, "Butyric acid induces apoptosis via oxidative stress in jurkat T-cells," Journal of Dental Research, vol. 89, no. 7, pp. 689-694, 2010.

[46] S. L. Camhi, P. Lee, and A. M. K. Choi, "The oxidative stress response," New Horizons: Science and Practice of Acute Medicine, vol. 3, no. 2, pp. 170-182, 1995.

[47] K. Nose and M. Ohba, "Functional activation of the egr1 (early growth response-1) gene by hydrogen peroxide," Biochemical Journal, vol. 316, no. 2, pp. 381-383, 1996.

[48] A. R. Bauskin, D. A. Brown, T. Kuffner et al., "Role of macrophage inhibitory cytokine-1 in tumorigenesis and diagnosis of cancer," Cancer Research, vol. 66, no. 10, pp. 49834986, 2006.

[49] T. A. Zimmers, X. Jin, E. C. Hsiao, S. A. McGrath, A. F. Esquela, and L. G. Koniaris, "Growth differentiation factor15/macrophage inhibitory cytokine-1 induction after kidney and lung injury," Shock, vol. 23, no. 6, pp. 543-548, 2005.

[50] J. B. Welsh, L. M. Sapinoso, S. G. Kern et al., "Large-scale delineation of secreted protein biomarkers overexpressed in cancer tissue and serum," Proceedings of the National Academy of Sciences of the United States of America, vol. 100, no. 6, pp. 3410-3415, 2003.

[51] S. Sperandio, S. Tardito, A. Surzycki, M. Latterich, and I. de Belle, "TOE1 interacts with p53 to modulate its transactivation potential," FEBS Letters, vol. 583, no. 13, pp. 2165-2170, 2009.

[52] N. Bidere, H. C. Su, and M. J. Lenardo, "Genetic disorders of programmed cell death in the immune system," Annual Review of Immunology, vol. 24, pp. 321-352, 2006.

[53] N. Venkatesan, "Pulmonary protective effects of curcumin against paraquat toxicity," Life Sciences, vol. 66, no. 2, pp. PL21-PL28, 1999.

[54] M. C. Matheson, J. A. Ellis, J. Raven, E. H. Walters, and M. J. Abramson, "Association of IL8, CXCR2 and TNF$\alpha$ polymorphisms and airway disease," Journal of Human Genetics, vol. 51, no. 3, pp. 196-203, 2006.

[55] W. I. de Boer, V. K. T. Alagappan, and H. S. Sharma, "Molecular mechanisms in chronic obstructive pulmonary disease: potential targets for therapy," Cell Biochemistry and Biophysics, vol. 47, no. 1, pp. 131-147, 2007.

[56] M. Bianchi, G. Fantuzzi, R. Bertini, L. Perin, M. Salmona, and P. Ghezzi, "The pneumotoxicant paraquat induces IL-8 mRNA in human mononuclear cells and pulmonary epithelial cells," Cytokine, vol. 5, no. 5, pp. 525-530, 1993. 
[57] H. Horiguchi, N. Mukaida, S. I. Okamoto, H. Teranishi, M. Kasuya, and K. Matsushima, "Cadmium induces interleukin8 production in human peripheral blood mononuclear cells with the concomitant generation of superoxide radicals," Lymphokine and Cytokine Research, vol. 12, no. 6, pp. 421-428, 1993.

[58] S. I. Okamoto, N. Mukaida, K. Yasumoto, H. Horiguchi, and K. Matsushima, "Molecular mechanism of interleukin-8 gene expression," Advances in Experimental Medicine and Biology, vol. 351, pp. 87-97, 1993. 

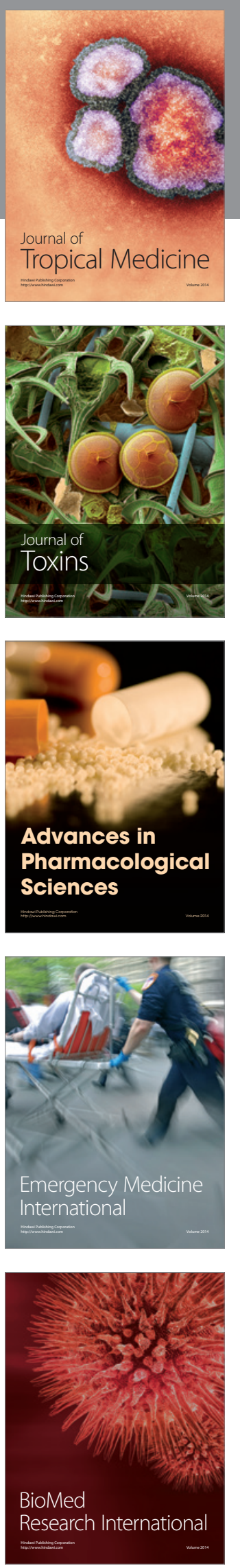
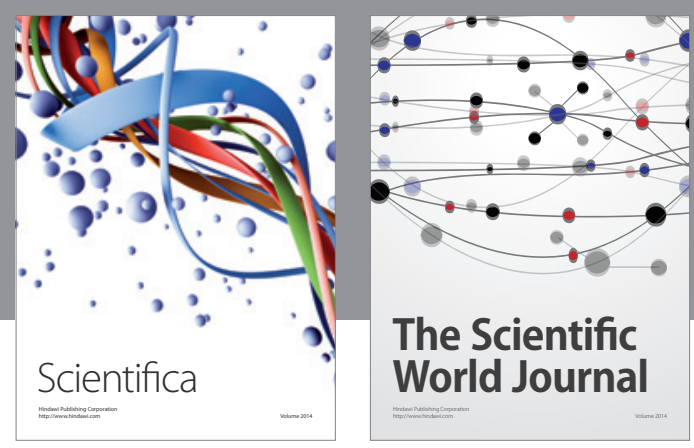

The Scientific World Journal
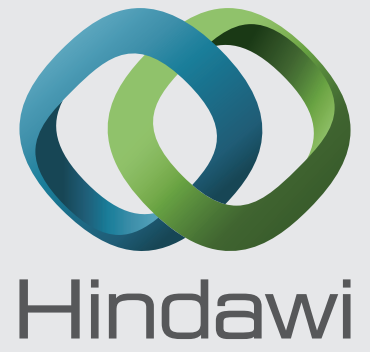

Submit your manuscripts at

http://www.hindawi.com
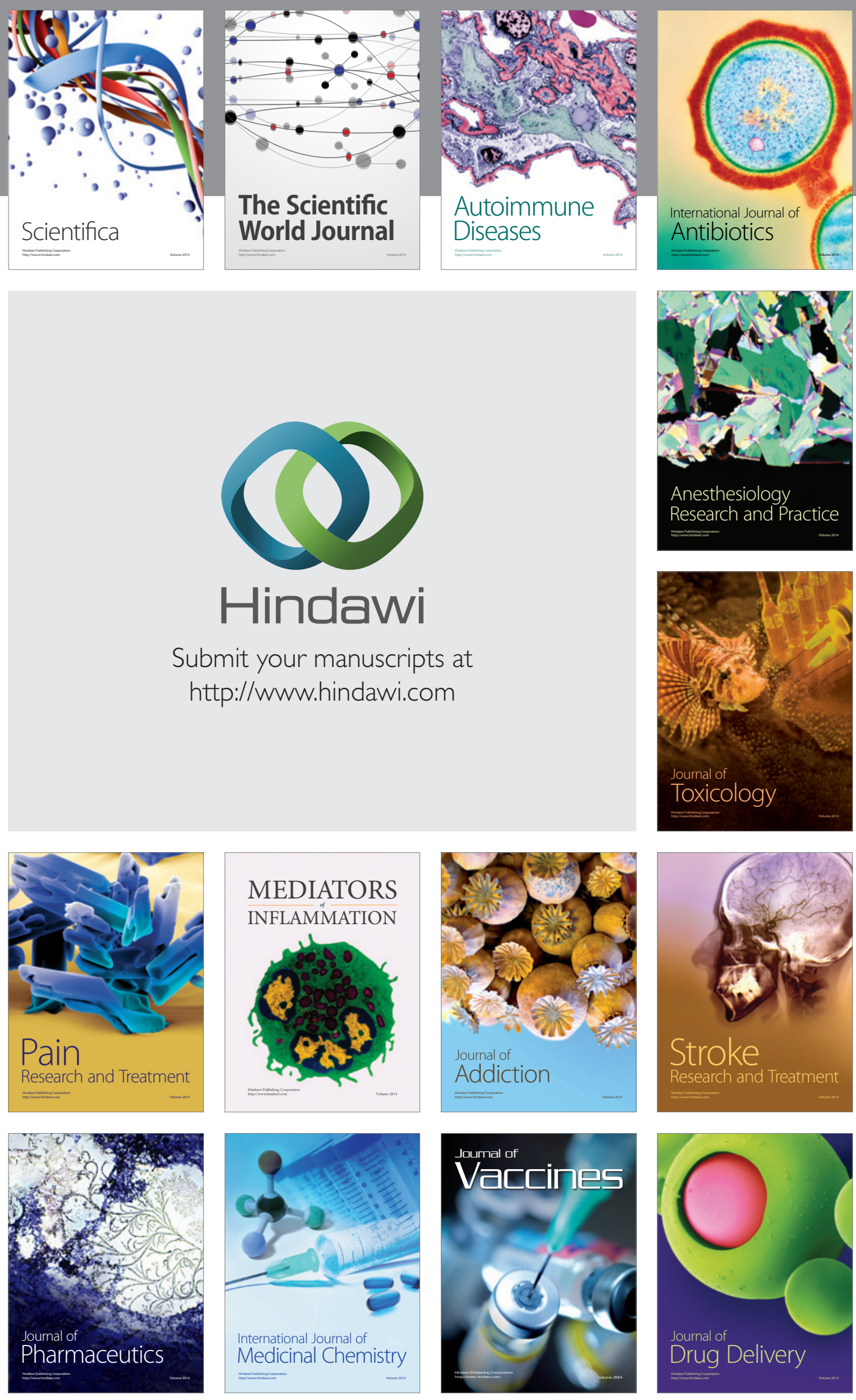